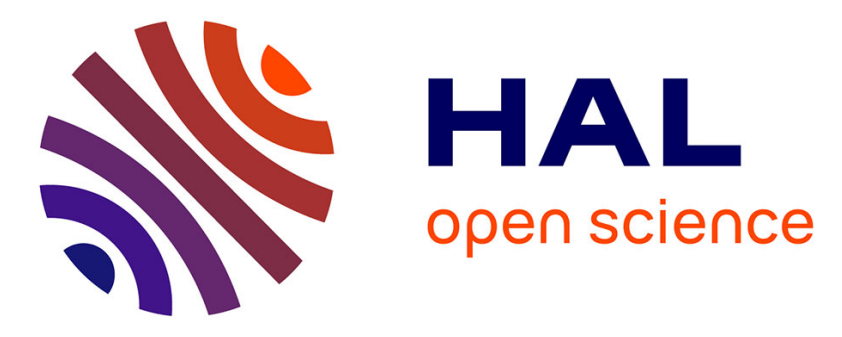

\title{
Building spaces for discussion: getting the diversity of practices speak
}

\author{
Camille Bachellerie, Danie Jon, Alexis Chambel, Camille Toulisse
}

\section{To cite this version:}

Camille Bachellerie, Danie Jon, Alexis Chambel, Camille Toulisse. Building spaces for discussion: getting the diversity of practices speak. International Ergonomics Association 21st Triennial Congress, Jun 2021, Vancouver, Canada. pp.438-445, 10.1007/978-3-030-74602-5_62 . hal-03277364

\section{HAL Id: hal-03277364 \\ https://hal.science/hal-03277364}

Submitted on 3 Jul 2021

HAL is a multi-disciplinary open access archive for the deposit and dissemination of scientific research documents, whether they are published or not. The documents may come from teaching and research institutions in France or abroad, or from public or private research centers.
L'archive ouverte pluridisciplinaire HAL, est destinée au dépôt et à la diffusion de documents scientifiques de niveau recherche, publiés ou non, émanant des établissements d'enseignement et de recherche français ou étrangers, des laboratoires publics ou privés. 


\title{
Building spaces for discussion: getting the diversity of practices speak
}

\author{
BACHELLERIE Camille [1] JON Danie [2-3] CHAMBEL Alexis [2-4] TOULISSE Camille[5] \\ 1 : Ergonomist, Ph.D student, Conservatoire national des arts et métiers, CREAPT, France \\ 2 : Ergonomist, Ph.D student, AECTT-EVS UMR 5600, Université Lumière Lyon 2, France \\ 3 : Kardham, France \\ 4 : Parcours Doctoral National en Santé Travail, France \\ 5 : Ergonomist, Head of the internal Occupational Health Service of Département de l'Ain, France
}

\begin{abstract}
This article aims at explaining the setting up and the progress of the Junior Practice in Reflection Committee of the SELF's "day of exchange on practices". Here we describe how the day took place in February 2020 in Paris. We are going to explain how the engineering of the discussion is organized and what effects are expected when we are talking about the practice of ergonomics. Beyond this description, our approach is to document about the engineering discussion around the implementation of a reflexivity on the practice among novice ergonomists.
\end{abstract}

Keywords: Discussion engineering, reflective practice, practice diversity, professional enrichment

\section{Introduction}

The Junior Practices in reflection Committee (JPR) was born out of a two-fold observation; the existence of problems specific to young practitioners and the lack of space to instruct those. From that basis, it was proposed to the SELF (French Speaking Ergonomics Society) to create a committee dedicated to exchanges on the practice of ergonomics for and by junior practitioners. This committee has a twofold objective of creating an ephemeral framework for exchanges between junior practitioners while at the same time articulating these exchanges with the various instances that make up the profession and manufacture the discipline. Since its creation in 2014 and at a rate of about three days per year, it has brought together nearly 200 participants from all over France but also from various fields of ergonomics practice (occupational health service, consultant, internal, doctoral student, etc.). Finally, these spaces of exchange have crossed borders, with a first office in Quebec from 2014 to 2017 and an office in Peru since 2018. The interest of this symposium is to present what has been developed by the committee in terms of exchanges on practice while opening this presentation to other forms of practice. These axes will take the form of four communications. The first communication will return to the theoretical foundations of the JPR Committee. The second paper will present the story of a young practitioner. Without wanting to be representative, it will serve as an example to show what is discussed in the JPR meeting days. The third communication will present the implementation of the exchange on practice, and we will be able to illustrate here the methodology we use and the intermediate objects that it mobilizes. The fourth communication will come back to the specificities of the deployment of the office in Peru and issues that this may raise.

This article represents the third part of a symposium; it is dedicated to the description of the discussion engineering method deployed by the JPRs during the days organized by the Committee. First of all, we will show how the French ergonomics context calls for the creation of different spaces for discussion on practice. Next, we will describe the different forms of discussion and why the JPR Commission has 
chosen the engineering of discussions on practice. Finally, we will concretely illustrate our point with an example of a day organized by the JPR in February 2020 in Paris.

\section{The challenge of spaces for debate in a context of diversity of practices}

The observation on the diversity of professional practices in ergonomics has been shared for many years in France (Daniellou, 2003, Daniellou, 2008, Falzon, 2019) and these different forms of practices and areas of specialization are recognized. The JPR are part of this tradition of taking a close interest in all forms of practices.

The practices conditions of ergonomist are various. Each one acts within its own regulatory and organizational frameworks, which will determine the room for maneuver allocated to them. These diverse practices conditions stem from the fact that ergonomists work in a variety of environments (institutional structures, occupational health service, job retention, engineering firms, research, etc.) but also have different areas of intervention: designing an aeronautical workshop in a factory, organizing the progress of a building site, keeping a person with disabilities in employment, preventing musculoskeletal disorders, designing a digital interface, etc. Sometimes, the diversity of these objects calls for the development of specific methods according to the sectors in which ergonomists work. Thus, some of them form associations to talk about a specific object: "It is therefore normal that there should be profession confrontations limited to the same type of object" (Daniellou, 2008, p. 13).

In this sense, ergonomists are grouped into different associations and the discussion held there can be of several kinds: conditions of practice, statutes, professions or even the objects of intervention. If we take up Yves Clot's expression (1999), these spaces consist of "making the profession speak" in order to draw up the rules of the profession among peers. Ergonomists can then talk about their successes and difficulties in establishing these crafts rules. Obviously, the aim of these groups is not to produce "generic lessons" but rather to showcase professional experiences, each time singular, but which may resonance with the experiences of peers.

The diversity of practices constitutes a richness for French ergonomics because it avoids the modelling of a universal form of intervention which should be applied everywhere and to everyone; on the contrary, it makes it possible to build a practice which is adaptable and can respond to the various situations encountered by ergonomists. However, this should not prevent ergonomists from thinking collectively about this practice. As Daniellou reminds us in 2008 in an introduction to the Journées de Bordeaux pour la Pratique: "The fact that every-one manages and that there is no reflexive capitalization anywhere, the idea that an intervention is different every time and that everything has to be rebuilt is the opposite of the idea of a profession. My position is that we need models which capitalize on what experience is likely to work in a given context and framework of constraints. From experience, i.e from the decantation of the lived experience of ergonomists who have been at the front in various situations" (Daniellou, 2008, p. 20).

However, the diversity of ergonomists' status, working conditions and areas of intervention may constitute a risk of isolation, particularly when it is a first experience. In this case, the first resource that appears to novice ergonomists is reference to academic models and methods. However, this resource remains limited, as these models and methods, which are rich in generic lessons, are constantly evolving according to the situation faced with. In this respect, opening spaces for reflexivity makes it possible to discuss these practices without falling into the pitfall of standardization. These spaces of reflexivity make it possible, through discussion, to develop what Yves Clot (1999) calls 
"gender" and "style": even if the overall model of an intervention remains the same, it must be constantly adapted to the situation, so everyone will develop a style according to "gender".

According to Daniellou (2008), the profession of ergonomist is the result of a construction of crafts rules that are themselves fueled by the practice: "The trade is therefore a collective work around "how we do in such and such a situation", around our activity in terms of difficulties in managing certain forms of situations" (p. 14-15). Thus, if we take up Daniellou's expression, these places of meeting and discussion can constitute "work of the craft".

According to Falzon (2019), the ergonomist's activity is arbitration: "How are decisions of opportunity made? What arbitration do I have to make at any given time?" (p. 120). This arbitration skill is developed through experience, which enables us to make relevant compromises in the situation: "Arbitration skill is one of the skills to be developed. There is what we wish to do, what we can really do in a situation and which we can judge ourselves acceptable, what colleagues may find acceptable, and then also what seems unacceptable. Arbitration decisions are decisions of the profession, of profession collectives." (Falzon, 2019, p. 121).

By making the diversity of practices speak, one is led to review one's own practice, to examine it differently in the light of what others are doing and thus to widen the scope of possibilities. However, the diversity of practices cannot be decreed; it is a process that is the result of the development of professional practices (Van Belleghem, 2008). The challenge here is therefore not only recognizing this diversity but also to collectively share these practices in order to contribute to their development: "We are relying on Yves Clot's proposal, which consist of recreating, in a way, diversity of doing things, so that can find their way around and share them" (Van Belleghem, 2008, p. 113). It means recognizing these practices as professional know-how, highlighting them, without considering them as deviations from what would be a 'norm'. This is what Yves Clot calls "the sense of doing well" (p. 117, 2019), where the development of work "well done", in the sense of the organization and the worker, lies in the existence of controversies over what makes these criteria. Here, as Christophe Dejours and Isabelle Gernet (2012) point out, these "spaces of deliberation" (p. 84) allow for debate and negotiation of rules, the creation of new knowledge and cooperation. The challenge here is therefore to integrate diversity in order to contribute to the process of diversification and development of practices.

\section{Building a space for discussion}

As we have just seen, the practice of ergonomics in France therefore exists in various forms and in various contexts of intervention. In order to discuss the diversity of ergonomics practice and to enable young practitioners to express the issues and questions that are specific to them (Cromer and al., 2016), the JPR commission proposes a "day of exchange on practice" up to three times a year. These days provide a framework for bringing together novice ergonomists to discuss and debate a theme, different for each day.

The purpose of these moments is not only discussion or expression. The challenge is to arrive at a reflexivity on practice (Schön, 1983), both individual and collective. To do this, it is first necessary to be able to offer the conditions "for the emergence and effective realization of the exchange of practices" (Cromer et al., 2016). Talking about one's practice also requires taking the "risk" of sharing one's experience, one's satisfaction or dissatisfaction with the intervention with others. Talking about one's practice would therefore also require talking about oneself and revealing oneself. Thus, the space for exchange on practice is not only a place to gather, but also a framework that exists thanks to the engineering of discussion (Ibid.), which guarantees a safe and constructive environment. This 
participates in the establishment of operating rules "in order to create a climate of listening, trust and benevolence, allowing everyone to express themselves freely" (Ibid.).

This discussion engineering is worked on in three stages: before, during and after the day (Ibid), and considers several structuring elements: the framework, the facilitation, the participants, and the interaction between these three elements.

The first stage is the preparation of the framework of the discussion space and the structuring of the roles (animator, participant, reciter). The commission is composed up to 5 members, and for each day two of them take the role of animator and a third person takes care of the logistics.

Throughout the day, the animators guide the participants towards reflexive work. They begin by setting a safe framework stating certain rules such as benevolence towards other participants. They then make sure that the time allocated to the different stages is respected and encourage everyone to speak.

Very often, the two remaining members participate in the day as participants in the sub-groups to regulate the exchanges and to help the other participants in the reflexivity. Indeed, this preparation time also allows the constitution of sub-groups from the list of participants. We pay particular attention to the fact that these sub-groups are made up of different areas of activity (consultants, in-home practitioners, etc.), always with the aim of promoting discussion between different forms of practices. This distribution also makes it easier for everyone to gain height. Each sub-group is structured around a reciter, whose storytelling is also worked on upstream in cooperation. The challenge is to structure the narrative into reflexive professional storytelling. Without this, they cannot play their role as boundary objects and allow a reflexive exchange on practice. This point is more detailed in the first two papers of this symposium.

Then, the theme to be discussed during the day is chosen either based on a survey addressed to young practitioners at the beginning of the year or according to the demands and needs emerging after previous days. The theme is divided into sub-questions to provide a reference point for the discussions during the day. These themes consider the diversity of ergonomic practices and are chosen so that they can be discussed for all forms of practices and intervention situations.

The second stage is the day's session. It is the time and space of exchange on practice and reflexive work that constitutes the main issue of the exchange day. After a brief presentation of the committee and the rules of operation, the day is divided into four steps:

- $\quad$ 1st step: Storytelling and questioning the participants' understanding.

- 2nd step: Sharing with the other participants about situations which the storytelling echoes in their own practice, followed by work on the theme addressed. Intermediate objects can be used to give substance to the discussion and as a support for the debates. Animators move between each sub-group to guide the discussion.

- 3rd step: Sharing of each person's work and taking height, assisted by the animators.

- 4th step: assessment of the day going around the table, where all participants are asked what they thought of the day (feedback, satisfaction, dissatisfaction) but above all what they retained (a key concept, an idea, etc.).

Finally, the third stage, the after-day stage, also contributes to the construction of the discussion space. It is a moment of assessment which, based on the course of the day, the feelings of the animators and participants members of the committee, the after-day discussions between the members but also on the feedback from the participants, allows the days to evolve in a perspective of 
improvement. By preserving and solidifying what works and by modifying the elements that may have caused problems or hindered the reflexive work, this is how each of the days evolves; not only the engineering of the discussion but also the themes and the emergence of new ones for the coming days. A report on the day is then communicated by the committee, which allows each participant to have a trace of the exchanges and allows the committee to have material for events and articles that are shared within the community.

\section{Description of the JPR discussion engineering methodology based on an example}

This section aims to illustrate how a day for exchange on practice unfolds. As an example, we describe here how it took place in February 2020 in Paris.

The theme chosen was "multidisciplinary in intervention". We then divided this theme in three subquestions to help the participants to explore it. This enables us to clarify the content of this exchange in giving an outline:

- Creating the conditions for the intervention: how does the ergonomist take position according to his/her possibilities to act and those of the other actors in the intervention?

- Can the ergonomist do everything? How do the boundaries of our practice move according to our intervention and the actors involved in?

- What methodologies and tools should be used to support this multi-professional collaboration?

To encourage discussion on these themes, we ask the participants to create a visual representation of their intervention along the day. We called these representations: "intervention maps" to represent the phenomena linked to the intervention in a spatial configuration, that would give meaning to the way in which the ergonomist acts. Participants are divided into three sub-groups, rather than a full group, to encourage reflection and discussion. We then divide the day into four main stages: First, each sub-group, based on a practitioner's experience, the other participants draw up an "intervention map" from the reciter's storytelling. Second, from the intervention maps that each participant individually developed, we ask the participants to create an intervention map together (Fig.1). Third, still in subgroup, we asked the participants to create a new map (Fig.2). This represents the ideal of the spaces, movements, and actions that the ergonomist could have made during the intervention. Finally, we meet all together for a plenary session. This debriefing takes place in three times: one rapporteur per group presents the last two maps to all the participants (Fig.3)

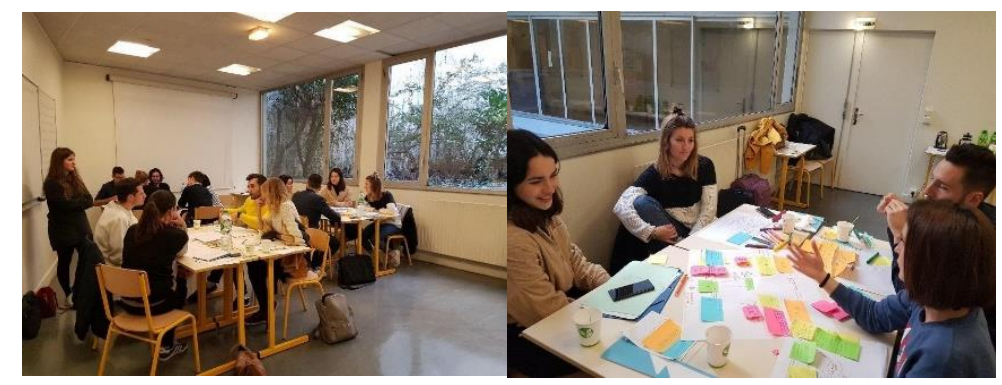

Fig. 1. Each group works on a "intervention map" based on the narrative. 


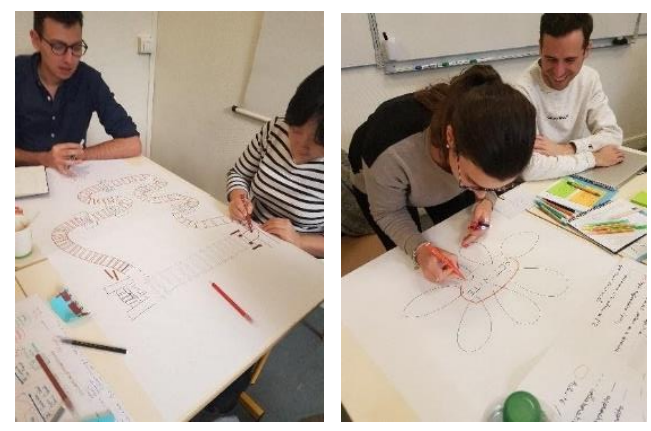

Fig. 2. examples of maps developed collectively in sub-groups.

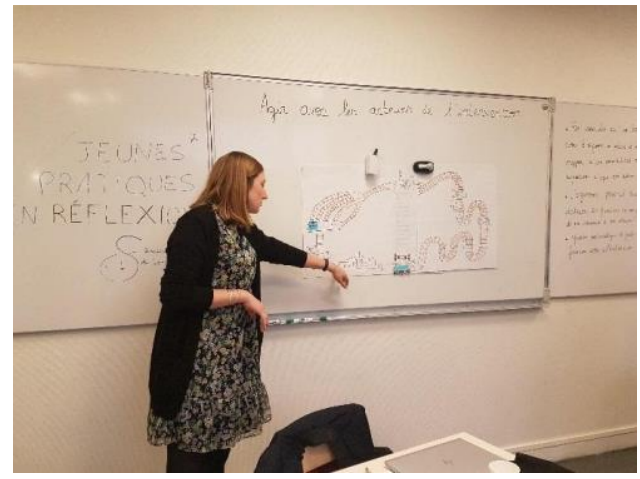

Fig. 3. whole group presentation of each group's intervention maps.

This is followed by a collective discussion about similarities and differences between all these maps. This allows us to take an overview of the particularities of each intervention that have been presented. Then, the animators take few minutes to underline the strong ideas that come out of the debate.

Finally, at the end of the day, we lead a round-table discussion to gather the opinions of each participant on the day's progress and content. Here is an example of verbatim: "Exchanges are free, allow us to realize that we are not alone and that we are facing the same difficulties. Discovering the interventions of others is really enriching. The format is great, thank you very much!"

\section{Conclusion}

Throughout the day, we ask the participants to write down their expectations regarding the proposed theme. This collecting step is crucial because it allows us to appreciate what the participants retain from the day and the elements that they will use for their own future interventions. Thus, different levels of feedback are identified: a very broad level of expectation that concerns ergonomics in general and its practice with great appeal for discussion among peers. We also reach a shared consensus on the need to consider the multidisciplinary in the interventions.

Thanks to this feedback, we can observe viewpoints changes on different aspects of practice. However, we do not know to what extent these changes in points of view give rise to real changes in practice. To really measure whether these effects are taking place, the Commission would need to adopt a diachronic approach to participants' practice, between a "before" and an "after" participation in a one-day event. While such knowledge would be very interesting for the development of the 
discussion engineering set up by the Commission, but an approach of this type would require a nonnegligible amount of time and investment and would take us away from the Committee's aims: to create a reflexive space for young practitioners and to diffuse this approach throughout our scientific and professional community.

Today, because of the health crisis, we are keen to develop our methodology so that it can be adapted to virtual meetings. If these remotely events cannot replace face-to-face discussions, it invites us to question ourselves on a new form of discussion engineering that we are going to set up during the 2020-2021's winter in order to keep the reflexivity of young practices alive.

Finally, more than ever in this context, we are committed to continuing to pro-mote the diversity of practices and their encounters, beyond our geographical borders. This is why a new office of the Commission has been set up in Peru; the challenge here is to take up elements that have already been developed by the Commission in order to adapt them to the local context of the practice of Peruvian ergonomics. This will be the content of the fourth and final paper of this symposium.

\section{References}

1. Daniellou F. (2003). "Dix ans de pratiques de l'ergonomie : avons-nous beaucoup changé ?" in Actes des Journées de Bordeaux pour la Pratique, Bordeaux, Mars 2003, p. 13-23

2. Daniellou F. (2008). " Diversité des domaines d'intervention, nouvelles pratiques de l'ergonomie, qu'avons-nous encore en commun ? " in Actes des Journées de Bordeaux pour la Pratique, Bordeaux, Mars 2008, p. 11-22

3. Clot, Y. (1999). La fonction psychologique du travail. Paris : Presses universitaires de France.

4. Clot Y. (2019). Les conflits de la responsabilité. In E. Bourdu, M. Lallement, P. Veltz and T. Weil, Le travail en mouvement. Presses des Mines, p. 112-121

5. Cromer D., Elwert L., Hubert K., Francou F., Couillaud S. (2016). De l'échange sur la pratique à son enrichissement. In : 51ème Congrès de la SELF, Marseille, France.

6. Dejours C. and Gernet I. (2012). Travail, subjectivité et confiance. Nouvelles Revue de Psychosociologie, $n^{\circ} 13$, p. 75-91

7. Falzon P. (2019). « Fil rouge JDB 219. Evolution des contextes et des pratiques d'intervention : vers différents métiers d'ergonomes ? "In Actes des Journées de Bordeaux pour la Pratique, Mars 2019, Bordeaux, p. 111-125

8. Schön, D. A. (1983). The reflective practitioner: How professionals think in action. New York: Ashgate.

9. Van Belleghem L. (2008). "Diversité des domaines d'intervention, nouvelles pratiques de l'ergonomie : qu'avons-nous encore en commun ? Fil rouge » in Actes des Journées de Bordeaux pour la Pratique, Mars 2008, p. 109-125 